\title{
Electrochemical Method for Producing Valuable Sulfur Compounds from Waste Materials
}

\section{Abduali Baeshov¹, Begzat Myrzabekov1, Arman Makhanbetov', Brajendra Mishra², Omirserik Baigenzhenov ${ }^{3}$, Vladimir Luganov ${ }^{3}$}

"D.V.Sokolsky Institute of Fuel, Catalysis and Electrochemistry" JSC, Almaty, Kazakhstan

${ }^{2}$ Worcester Polytechnic Institute, Worcester, MA, USA

${ }^{3}$ Kazakh National Research Technical University Named after K.I. Satpayev, Almaty, Kazakhstan Email: baeshov48@mail.ru, myrzabekbegzat@mail.ru,armanmab@mail.ru,bmishra@wpi.edu, omir_88@mail.ru, v_luganov@mail.ru

How to cite this paper: Baeshov, A., Myrzabekov, B., Makhanbetov, A., Mishra, B., Baigenzhenov, O. and Luganov, V. (2017) Electrochemical Method for Producing Valuable Sulfur Compounds from Waste Materials. International Journal of Nonferrous Metallurgy, 6, 17-26. https://doi.org/10.4236/ijnm.2017.62002

Received: February 11, 2017

Accepted: April 25, 2017

Published: April 28, 2017

Copyright $\odot 2017$ by authors and Scientific Research Publishing Inc. This work is licensed under the Creative Commons Attribution International License (CC BY 4.0).

http://creativecommons.org/licenses/by/4.0/

\begin{abstract}
Method and mechanism for the formation of sulfur compounds during the process of sulfur electrochemical dissolution has been studied, including a technique for the production of composite sulfur-graphite electrode. Along with these, a 3D design is presented in the unit that was used to perform electrolytic reduction, using composite sulfur-graphite electrode. For the first time, a study was carried out for the simultaneous reactions of electroreduction and electrooxidation of sulfur at the sulfur-graphite electrode in sulfurous environment in the same electrolytic bath, with separate electrode spaces. Influences of current density, acid concentration and electrolyte temperature were studied, and it was demonstrated that sulfur is reduced in cathode chamber with formation of hydrogen sulfide gas, and is oxidized in the anode chamber with formation of sulfite and sulfate ions. It has been shown that the methods we propose can be used to produce important sulfur compounds through electrochemical dissolution of specially designed sulfur-graphite electrode.
\end{abstract}

\section{Keywords}

Sulfur, Electroreduction, Sulfur-Graphite Electrode, Polarization Curve

\section{Introduction}

Effective use of natural resources, neutralization of production waste and environment protection is the top-priority tasks of today's chemical industry. As the rate of crude production grows, the problem of contamination of land and water resources by oil waste becomes more acute. It is commonly known that most of 
Kazakhstani crude is high in sulfur content. For instance, presence of sulfur compounds in fuel materials leads to corrosion of combustion engines, reduces performance and also affects the environment, which necessitates stripping of crude from sulfur. Currently a large quantity of sulfur waste in a solid state has accumulated in Kazakhstan. Consequently, this waste consists of toxic sulfur compounds; therefore its extended open unprotected storage can cause environmental degradation. In the light of the above, the pursuance of research aimed at development of new methods for treatment of sulfur-containing waste is critically important.

Production of leading-edge sulfur compounds using electrochemical methods is of great practical significance for the industry. However, considering that sulfur is a dielectric and some difficulties can be experienced during its electrochemical polarization, transforming the element into electrochemically active state and developing electrochemical methods of processing sulfur-containing waste with subsequent production of its compounds emerges as a vital issue.

A great number of papers have been devoted to studies of electrochemical behavior of sulfur ions and its compounds that are presented in monographs and scientific works of many authors [1] [2] [3] [4] [5]. Nevertheless, thus far, due to the abovementioned technical constraint that sulfur does not conduct electrical current and that it is not electrochemically active, its electrochemical behavior has not been thoroughly investigated.

This work aims at improvement of the method for production of sulfur- graphite electrode with subsequent cathode and anode polarization for synthesis of industrially significant sulfur compounds.

\section{Experimental}

This work proposes a method for production of sulfur-graphite electrode that is updated and improved in comparison with what had been proposed in previous works of the authors. In the course of electrolysis of composite sulfur-graphite electrode, using a method proposed by the authors earlier, certain difficulties emerged due to their shapelessness and it was difficult to attach robust current leads to the electrodes resulting in embrittlement and friability of the anode [6]. At the same time, if the composition of produced composite sulfur-graphite electrode is changed from the sulfur and graphite ratio of 1:1 in either direction, then in case of increased sulfur content, electrical conductivity property changes for the worse, and in case of increased graphite content the bonding property of the composite sulfur-graphite electrode deteriorates. Taking into account the above disadvantages, an improved method for production of sulfur-graphite electrodes was developed. This method of production is detailed below.

Graphite and sulfur are heated in the dry state (to the melting point of sulfur) in separate vessels to $110^{\circ} \mathrm{C}-120^{\circ} \mathrm{C}$ (grinding of sulfur to powdery condition is not required). Hot graphite is poured into molten sulfur and mixed. Prepared mixture is poured into special dies in such a way that the current lead is positioned in the center of the manufactured electrode. The electrode is cooled at room temperature to setting. It is to be noted that for better attachment of the 
current lead, an additional reinforcement is placed in the center of electrode. Thus sulfur-graphite electrode manufactured using the described method is free of the above disadvantages.

In the process of electrolysis, surface of sulfur-graphite electrode is repeatedly renewed because of electrodissolution and subsequent conversion of sulfur into solution and falling of graphite to the bottom of electrolytic bath in the sludge. Precipitated graphite powder is fully suitable for production of a new electrode.

Use of graphite for production of sulfur-graphite electrodes lends sulfur - a dielectric- attain electrochemical activity. By polarizing sulfur-graphite electrodes in water solutions and by varying the conditions of electrolysis we create a capability of producing not just sulfur compounds but also pure sulfur from chemically contaminated sulfur.

Research work was carried out in galvanostatic mode in temperature-controlled electrolytic bath made of organic glass with anode and cathode spaces separated by a bipolar membrane "BM". Figure 1 shows schematic representation of the unit designed for investigation of effects that electrochemical parameters have on behavior of elemental sulfur under electrochemical polarization.

This work, through the use of sulfur-graphite electrode, both as anode and cathode, during electrolysis, made it possible to simultaneously complete two processes with further synthesis of respective sulfur compounds. It means that during electrolysis in cathode chamber a process of sulfur reduction to hydrogen sulfide takes place, and in the anode space sulfur oxidizes to sulfite and sulfate ions.

Practical utility of producing hydrogen sulfide by cathodic polarization of composite sulfur-graphite electrodes is high, in the sense that by means of the produced gas, it is possible to get chemically ultrapure sulfur that is widely used in pharmaceutics, radio engineering (in manufacturing semiconductors) and other sectors of national economy and industry. It is possible also to produce

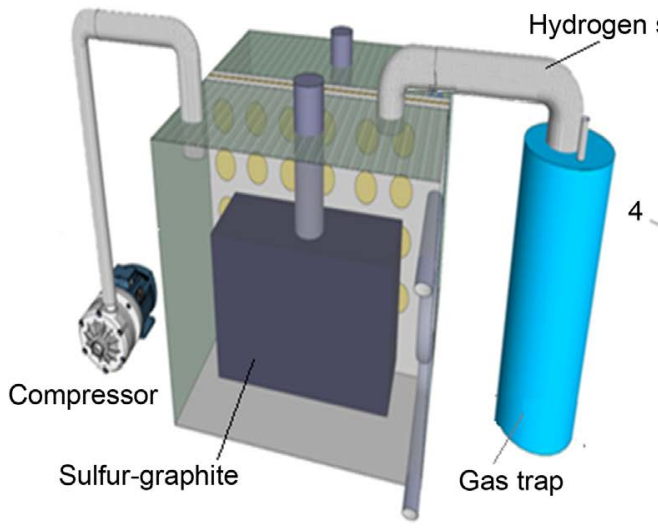

(a)

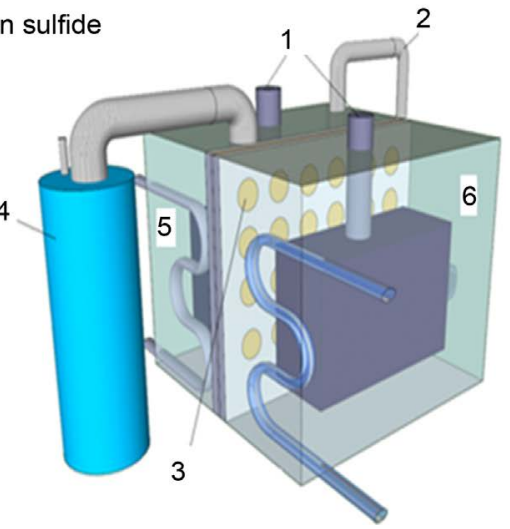

(b)

Figure 1. Unit for research of electrochemical behavior of elemental sulfur in water solutions (a) front view; (b) rear view): 1- composite sulfur-graphite electrodes, 2- compressor, 3- bipolar membrane BM, 4- gas trap unit for entrapping of hydrogen sulfide gas, 5 cathode chamber, 6- anode chamber. 
metallic sulfides used in ore benefication and production of paints. In this context research of cathodic behavior of sulfur becomes the matter of current interest.

Figure 2 shows a composite sulfur-graphite electrode with 3:1 ratio manufactured using the abovementioned method.

Figure 3 shows microphotographs of the produced electrode. In microphotographs a and b, one can see particles of sulfur (whitish color) and graphite (black color). Microphotograph 'a' is taken at a magnification of 100X, and microphotograph 'b' at $200 \times$.

\section{Results and Discussion}

A research was performed on sulfur oxidation-reduction processes in water solutions by graphing polarization curves in potentiodynamic mode.

Analysis of potentiodynamic polarization curves was performed using an integrated machine-IPC 2000 potentiostat consisting of a measuring potentiostatic unit and a personal computer with specially installed software in temperature-controlled glass cell of “ЯЭС - 2" brand. Composite PTFE coated sulfurgraphite electrode $(S=4 \mathrm{~mm})$ with $3: 1$ weight ratio was used as main electrode.

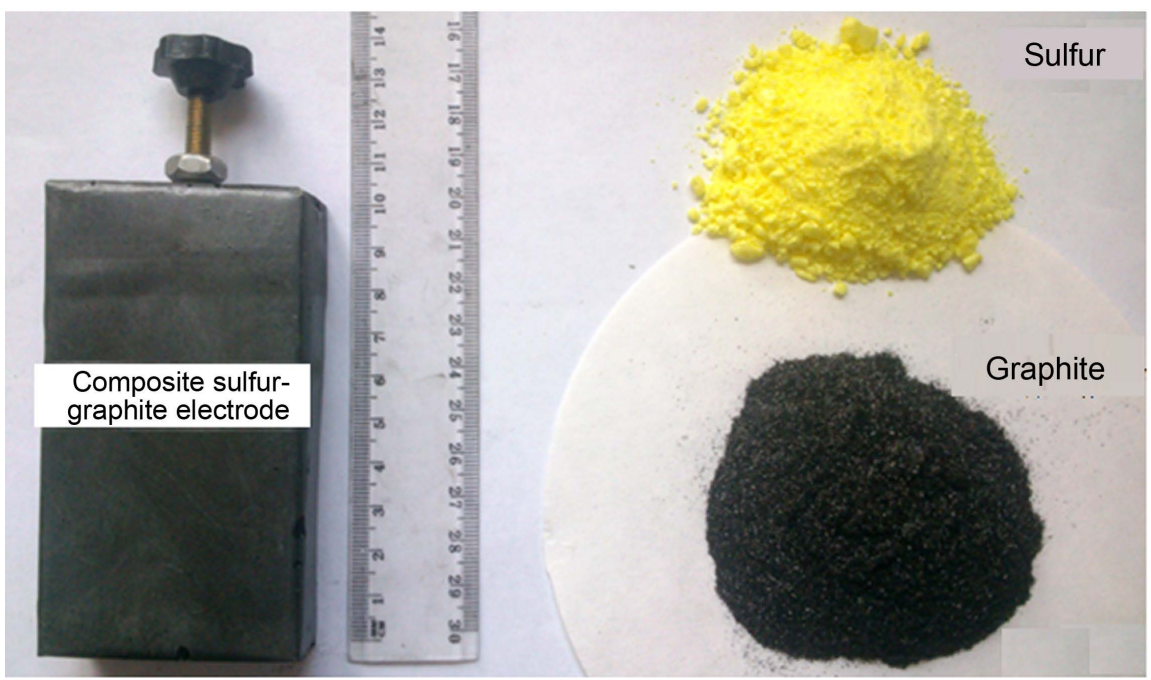

Figure 2. Composite sulfur-graphite electrode with 3:1 ratio.

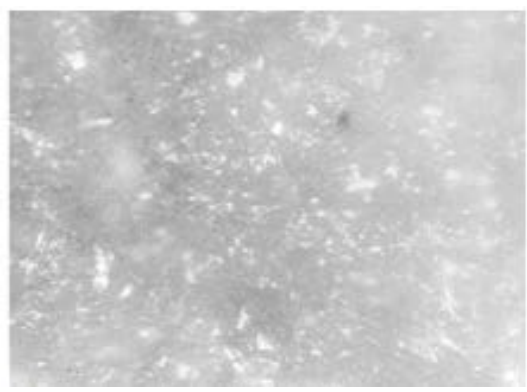

(a)

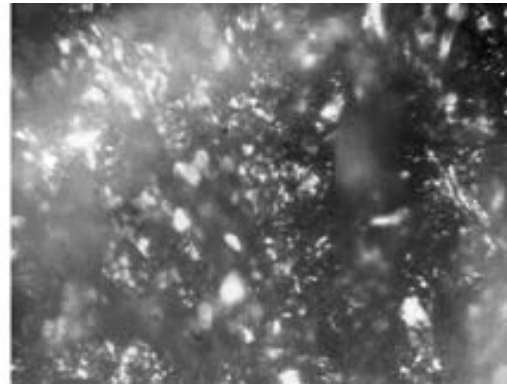

(b)

Figure 3. Microphotograph of a composite sulfur-graphite electrode at magnification of $100-200 x$ 
Silver-silver chloride electrode was used as the reference electrode, and the function of the auxiliary electrode was fulfilled by a platinum electrode. Potentials' values are indicated in relation to the silver-silver chloride electrode $\left(\mathrm{E}^{\circ}=\right.$ " + $0.203 \mathrm{~V})$.

Before each experiment, surface of the electrodes was polished by micronic polishing paper. For the purpose of studying electrochemical behavior of sulfur-graphite electrodes in sulfurous environment, polarization curves were graphed under the conditions of $1.0 \mathrm{M}$ sulfuric acid and a rate of linear sweep of $50 \mathrm{mV} / \mathrm{s}$ at solution temperature of $25^{\circ} \mathrm{C}$.

Fiugre 4 represents a cyclic cathode-anode polarization curve for a composite sulfur-graphite electrode in 1.0 M solution of sulfuric acid. As can be seen from the figure, the plotted cyclic cathode-anode polarization curve for the electrode shows the process of hydrogen release in cathode direction of polarogram. Where the curve changes its direction from cathode zone to anode zone before the potential of oxygen release, there are no oxidation processes observed. However, on sulfur-graphite electrode, release of hydrogen sulfide takes place simultaneously with the process of reduction of hydrogen ions.

Figure 5 shows a cyclic anode-cathode potentiodynamic polarization curve for sulfur-graphite electrode in $1.0 \mathrm{M}$ solution of sulfuric acid. On sulfur-graphite electrode before the potential of oxygen release at “+” $1625 \mathrm{mV}$ oxidation current is registered. According to our hypothesis (or expectations), reactions of sulfur oxidation with formation of sulfite and sulfate ions according to the Equations (1-3) are indicative for the stated values of potential. The results of electrolysis carried out under galvanostatic conditions indicate that during anode polarization in sulfurous environment oxidation of sulfur-graphite electrodes runs with formation of sulfite and sulfate ions:

$$
\mathrm{S}^{\circ}+3 \mathrm{H}_{2} \mathrm{O}-4 \mathrm{e} \rightarrow \mathrm{SO}_{3}^{2-}+6 \mathrm{H}^{+}
$$

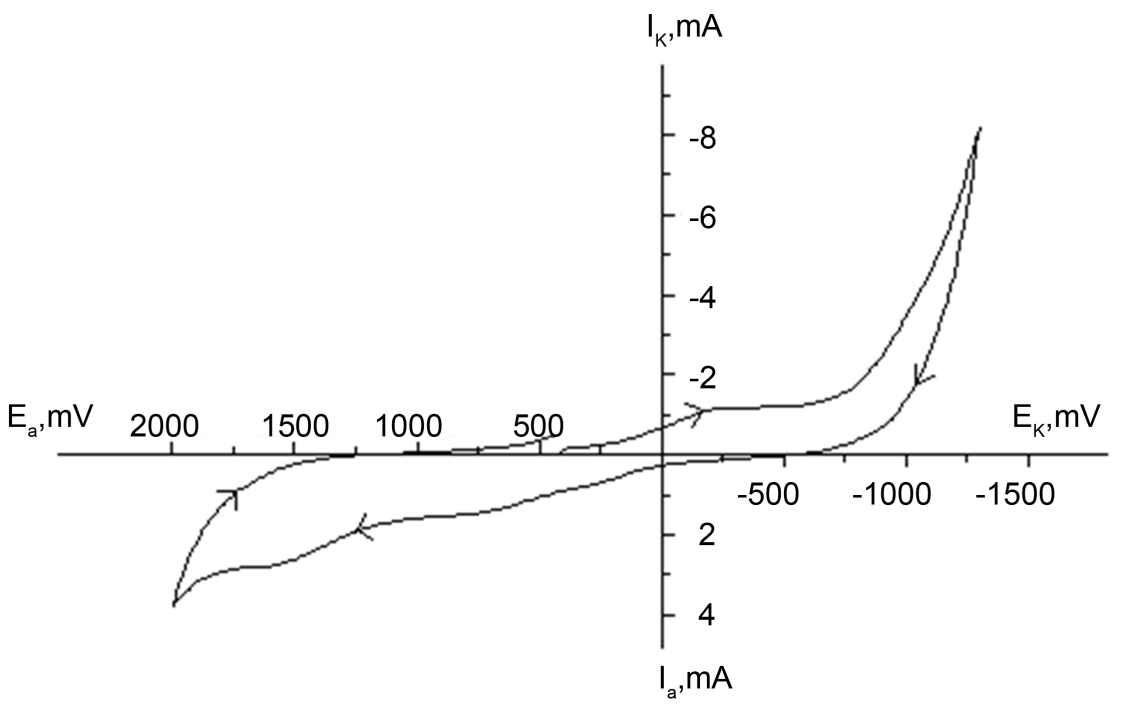

Figure 4. Cyclic cathode-anode polarization curve for sulfur-graphite electrode in sulfuric acid solution. 


$$
\begin{gathered}
\mathrm{SO}_{3}^{2-}+\mathrm{H}_{2} \mathrm{O}-2 \mathrm{e} \rightarrow \mathrm{SO}_{4}^{2-}+2 \mathrm{H}^{+} \\
\mathrm{S}^{\circ}+4 \mathrm{H}_{2} \mathrm{O}-6 \mathrm{e} \rightarrow \mathrm{SO}_{4}^{2-}+8 \mathrm{H}^{+}
\end{gathered}
$$

At high values of current density sulfur-graphite electrodes dissolve with formation of sulfate ions. However, the process runs at the potential of oxygen release.

In case of shifting the potential from the anode zone back to the cathode zone at the potential of "+" $1000 \mathrm{mV}$ we observed reduction current that corresponds to the reaction of reverse reduction of sulfite ions to sulfur in its elemental state:

$$
\mathrm{SO}_{3}^{2-}+6 \mathrm{H}^{+}+4 \mathrm{e} \rightarrow \mathrm{S}^{\circ}+3 \mathrm{H}_{2} \mathrm{O}
$$

When the potentials are "-" $1000 \mathrm{mV}$ and higher, we observed hydrogen release current. At the same time, release of hydrogen sulfide was noted by appearance of characteristic odor and confirmed by chemical analysis of gas. The process of hydrogen sulfide formation runs according to the following reactions:

$$
\begin{gathered}
\mathrm{S}^{\circ}+2 \mathrm{e}^{-} \rightarrow \mathrm{S}^{2-} \\
\mathrm{S}^{2-}+2 \mathrm{H}^{+} \rightarrow \mathrm{H}_{2} \mathrm{~S} \\
\mathrm{~S}^{\circ}+2 \mathrm{H}^{+}+2 \mathrm{e}^{-} \rightarrow \mathrm{H}_{2} \mathrm{~S} \uparrow \uparrow
\end{gathered}
$$

Since in our work we simultaneously studied the processes of anode oxidation and cathode reduction of sulfur-graphite electrode in one electrolytic bath with separated anode and cathode spaces, the attained results are presented together. Below we present the results of cathodic reduction of elemental sulfur in solution of sulfuric acid to support the foregoing. Hydrogen sulfide that is formed on cathode is trapped through a glass tube inside the gas trap (Figure 1, 4-gas trap). Produced gas accumulates in $0.5 \mathrm{M}$ solution of $\mathrm{NaOH}$. Quantity of the product after electrolysis was determined by the potentiometric method.

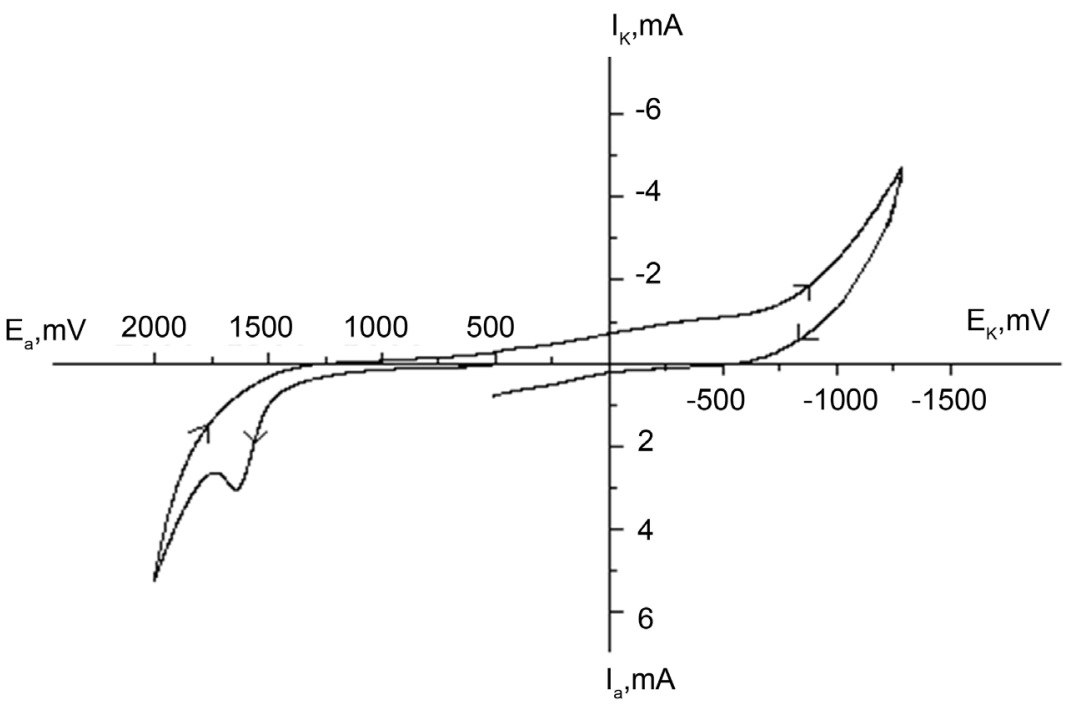

Figure 5. Cyclic anode-cathode polarization curve for sulfur-graphite electrode in sulfuric acid solution. 
In the course of electrolysis we explored the effect that density of cathode current has on current efficiency during formation of sulfide ions within the range of $25-200 \mathrm{~A} / \mathrm{m}^{2}$ on the process of electrochemical behavior of sulfur in $0.3 \mathrm{M}$ solution of $\mathrm{H}_{2} \mathrm{SO}_{4}$ (Table 1). Maximum current efficiency of sulfur reduction is registered at current density of $150 \mathrm{~A} / \mathrm{m}^{2}$, and it amounts to $23.1 \%$. At current densities over $150 \mathrm{~A} / \mathrm{m}^{2}$, current efficiency of hydrogen sulfide formation decreases due to increase in the rate of side reactions mainly through reduction of hydrogen ions.

Effect of concentration of sulfuric acid on current efficiency of formation of sulfide ions (Table 2) was studied. As is seen from the provided table, maximum current efficiency during formation of sulfide ions is registered at concentration of sulfuric acid of $0.1 \mathrm{M}$. At concentrations above $0.1 \mathrm{M}$ we observed decreased values of current efficiency during formation of sulfide ions that is explained by fall of overvoltage of hydrogen ions discharge.

Table 3 provides the results attained in the course of studying the effect that electrolyte temperature has on current efficiency during formation of sulfide ions. As the temperature increases, increase in value of current efficiency from formation of sulfide ions is observed. Maximum value of CE during formation of sulfide ions, amounting to $56 \%$, is observed at temperature of $65^{\circ} \mathrm{C}$.

Next, we explored electrochemical oxidation of elemental sulfur in course of anode polarization in solution of sulfuric acid using a composite current-conductive sulfur-graphite electrode. Electrolysis parameters (current density and concentration of sulfuric acid) that influence the process of anodic oxidation of sulfur were studied.

Methods for analyzing the solution that is produced during electrolysis in anode space are provided below. The results of preliminary research show that during anodic polarization of elemental sulfur, using the method of electrolysis

Table 1. Effect of current density on current efficiency during formation of sulfide ions of cathode polarized composite sulfur electrode: $\tau=5 \mathrm{~h}, \mathrm{t}=25^{\circ} \mathrm{C}, \mathrm{C} \mathrm{H}_{2} \mathrm{SO}_{4}=0.3 \mathrm{M}$.

\begin{tabular}{rrrrrr}
\hline $\mathrm{i}, \mathrm{A} / \mathrm{m}^{2}$ & 25 & 50 & 100 & 150 & 200 \\
$\mathrm{CE}, \%$ & 9.7 & 13.5 & 23.2 & 23.1 & 12.1 \\
\hline
\end{tabular}

Table 2. Effect of concentration of sulfuric acid on current efficiency during formation of sulfide ions of cathode polarized composite sulfur electrode: $\mathrm{i}=153 \mathrm{~A} / \mathrm{m}^{2}, \mathrm{t}=25^{\circ} \mathrm{C}, \tau=3$ h.

\begin{tabular}{cccccc}
\hline C, $\mathrm{M}$ & 0.1 & 0.2 & 0.3 & 0.4 & 0.5 \\
\hline $\mathrm{CE}, \%$ & 37.8 & 33.2 & 20.1 & 19.8 & 10 \\
\hline
\end{tabular}

Table 3. Effect of electrolyte temperature on current efficiency during formation of sulfide ions of cathode polarized composite sulfur electrode: $\mathrm{i}=153 \mathrm{~A} / \mathrm{m}^{2}, \tau=5 \mathrm{~h}, \mathrm{C} \mathrm{H}_{2} \mathrm{SO}_{4}$ $=0.3 \mathrm{M}$.

\begin{tabular}{cccccc}
\hline $\mathrm{t},{ }^{\circ} \mathrm{C}$ & 25 & 35 & 45 & 55 & 65 \\
\hline $\mathrm{CE}, \%$ & 23 & 38.5 & 41.8 & 48.0 & 56 \\
\hline
\end{tabular}


in sulfuric acid solution, sulfur actively dissolves forming $\mathrm{SO}_{3}^{2-}$ and $\mathrm{SO}_{4}^{2-}$ ions according to reactions (1), (2) and (3).

Table 4 provides the results of a study on what effect current density in the range of $25-250 \mathrm{~A} / \mathrm{m}^{2}$ has on the process of sulfur oxidation in $0.3 \mathrm{M}$ solution of $\mathrm{H}_{2} \mathrm{SO}_{4}$. As is seen from the figure, maximum $\mathrm{CE}$ value during formation of sulfate ions was registered at $150 \mathrm{~A} / \mathrm{m}^{2}$, and it amounts to $79 \%$.

Table 5 represents the data on how CE of formation of sulfate ions is affected by acid concentration within the range of $0.1-0.5 \mathrm{M}$. According to the results of the study, current efficiency of formation of sulfate ions rises with the increase in concentration of sulfuric acid up to a maximum value of $94.9 \%$.

\section{Analysis of Produced Compounds}

Physico-chemical and chemical methods were used to identify the products formed after electrolysis. To perform the analysis we used the weight method, the acid-base titration method, photocolorimetric and potentiometric methods [7]-[13]. Hydrogen sulfide gas that formed in the process of electrolysis in cathode chamber was identified by means of the potentiometric method. To that end hydrogen sulfide was passed through the alkaline solution of $0.5 \mathrm{M} \mathrm{NaOH}$. Resultant sulfide ions were analyzed using sulfide-selective electrode by bringing $\mathrm{pH}$ to 9.2 with help of borax buffer. Sulfate ions formed in the anode chamber and change of concentration of sulfuric acid solution were determined in the following manner: $5 \mathrm{ml}$ of aliquot was taken and acid concentration, using the method of acid-base titration was established. Sulfate ions were precipitated by hot barium acid, then it was filtered by Blue ribbon, and the formed deposit at temperature of $750^{\circ} \mathrm{C}$ was burned for an hour and weighed.

Phase composition and structure of sulfur compounds obtained as the result of electrolysis were determined using the method of X-ray phase analysis. The research was carried out using the GPDR-3 (general purpose diffractometer) with X-ray tube 2.0. Detector feed angle range was measured using goniometric scale of the installation and recorded with a self-recording chart paper of the potentiometer. Interpretation of the obtained X-ray pattern was performed with the aid of the ASTM American card index. Elemental composition of the obtained product was analyzed using a standard scanning electron microscope

Table 4. Effect of current density on CE of dissolution of composite sulfur-graphite electrode with formation of sulfate ions in solution of sulfuric acid: $\tau=5 \mathrm{~h} ; \mathrm{t}=25^{\circ} \mathrm{C}$; C $\left(\mathrm{H}_{2} \mathrm{SO}_{4}\right)=0.3 \mathrm{M}$.

\begin{tabular}{rccccc}
\hline $\mathrm{i}, \mathrm{A} / \mathrm{m}^{2}$ & 25 & 50 & 100 & 150 & 200 \\
\hline $\mathrm{CE}, \%$ & 27.5 & 35.0 & 38.9 & 79.0 & 38.2 \\
\hline
\end{tabular}

Table 5. Effect of concentration of sulfuric acid on current efficiency of oxidation of composite sulfur-graphite electrode: $\mathrm{i}=153 \mathrm{~A} / \mathrm{m}^{2}, \mathrm{t}=25^{\circ} \mathrm{C}, \tau=3 \mathrm{~h}$.

\begin{tabular}{cccccc}
\hline C, $\mathrm{M}$ & 0.1 & 0.2 & 0.3 & 0.4 & 0.5 \\
\hline $\mathrm{CE}, \%$ & 79.0 & 84.8 & 94.9 & 93.7 & 93.1 \\
\hline
\end{tabular}


(SEM) JSM-5300LV manufactured by JEOL company, which enables to establish elemental composition of samples with accuracy of \pm 1 at $\%$.

\section{Conclusions}

In summary, it is emphasized that a research was conducted to explore electrochemical behavior of sulfur-graphite electrode simultaneously in cathode chamber and anode chamber in sulfurous solution for the first time. The results obtained by means of plotting cyclic potentiodynamic polarization curves and analyzing the solution after electrolysis have indicated that anodic oxidation of sulfur takes place at " + " $1625 \mathrm{mV}$ and at the potential of oxygen release, cathodic reduction respectively takes place at the potential of hydrogen release. Reduction products are hydrogen sulfide and sulfide ions. Oxidation products are sulfite and sulfate ions. It was established that in sulfurous environment in the course of cathodic polarization, sulfur being a part of composite current-conductive electrode, cathodically reduces and hydrogen sulfide is formed.

It is demonstrated that under optimum conditions, current efficiency during sulfur reduction with formation of sulfide ions amounts to $56 \%$. Based on the research findings it is possible to develop a technology for production of hydrogen sulfide from technically contaminated elemental sulfur and metal sulfides. Hydrogen sulfide is the feedstock for production of pure elemental sulfur.

It was established that current efficiency of formation of sulfate ions during anodic polarization of composite sulfur-graphite electrode in sulfuric acid solution reaches $94.9 \%$. Template is used to format your paper and style the text. All margins, column widths, line spaces, and text fonts are prescribed; please do not alter them. You may note peculiarities. For example, the head margin in this template measures proportionately more than is customary. This measurement and others are deliberate, using specifications that anticipate your paper as one part of the entire journals, and not as an independent document. Please do not revise any of the current designations.

\section{References}

[1] Baeshov, A., Zhdanov, S.I. and Tulebayev, A.K. (1997) Electrochemistry of Sulfur and Its Compounds. Gylym, Almaty, 160.

[2] Bayeshov, A.B., Omarova, A. and Kapsalyamov, B. (2004) Ecological Problems of the Oil Industry Tengizchevroil. The 3 rd Scientific Conference of Higher Educational Institutions of South Kazakhstan, Shymkent, Vol. 7, 65-69.

[3] Bayeshov, A.B., Omarova, A.A, Bayeshova, S. and Kapsalyamov, B. (2004) Electrochemical Behavior of Elemental Sulfur in an Alkaline Medium at a Cathodic Polarization. International Scientific-Practical Conference of Young Scientists "Chemistry and Chemical Technology", Almaty, 70-72.

[4] Bayeshov, A.B., Asabayeva, Z.K., Bayeshova, S.A. and Nogerbekov, B.Y. (2008) Cathodic Sulfur Recovery in a Solution of Sodium Carbonate. 4th International Beremzhanov Conference on Chemistry and Chemical Technology, Karaganda, 133136.

[5] Manan, N.S.A., Aldous, L., Alias, Y., Murray, P., Yellowlees, L.J., Lagunas, M.C. and 
Hardacre, C. (2011) Electrochemistry of Sulfur and Polysulfides in Ionic Liquids. The Journal of Physical Chemistry B, 115, 13873-13879.

[6] Assabayeva, Z.K. (2010) Development Methods for the Synthesis of Inorganic Sulfur Compounds by Electrochemical Method. PhD Dissertation, Almaty, 26.

[7] Lurie, Y. (1973) Standardized Methods of Water Analysis. Chem., Moscow, 202205.

[8] A.P. Kreshkov, Fundamentals of Analytical Chemistry, Qualitative and quantitative analysis, Chem., Moscow, 1965, 412-413.

[9] Charlot, G. (1969) Methods of Analytical Chemistry. Quantitative Analysis of Inorganic Compounds. 2nd Edition, Chem., Moscow, 668.

[10] Vasiliyev, V.P. (1989) Analytical Chemistry in 2 Parts. Physical and Chemical Methods of Analysis. Higher School, Moscow, 384.

[11] Busev, A.I. (1982) Analytical Chemistry of Sulfur. Chem., Moscow, 622.

[12] Williams, W.J. (1982) Definition of Anions. Chem., Moscow, 622.

[13] Lurie, Y. and Rybnikova, A.I. (1953) Chemical Analysis of Industrial Wastewater. Chem., Moscow, 79-80.

\section{Submit or recommend next manuscript to SCIRP and we will provide best} service for you:

Accepting pre-submission inquiries through Email, Facebook, LinkedIn, Twitter, etc. A wide selection of journals (inclusive of 9 subjects, more than 200 journals)

Providing 24-hour high-quality service

User-friendly online submission system

Fair and swift peer-review system

Efficient typesetting and proofreading procedure

Display of the result of downloads and visits, as well as the number of cited articles

Maximum dissemination of your research work

Submit your manuscript at: http://papersubmission.scirp.org/

Or contact ijnm@scirp.org 